\title{
Death by Water: Precautionary Water Submersion for Intravitreal Injection of Retinoblastoma Eyes
}

\author{
Jasmine H. Francis ${ }^{*}, 1$, Xiaoliang L. Xu ${ }^{2}$, Y. Pierre Gobin ${ }^{3}$, Brian P. Marr ${ }^{1,4}$, Scott E. Brodie ${ }^{5}$ and \\ David H. Abramson ${ }^{1,4}$
}

${ }^{I}$ Ophthalmic Oncology Service, Memorial Sloan-Kettering Cancer Center, New York, NY, USA

${ }^{2}$ Department of Pathology, Memorial Sloan-Kettering Cancer Center, New York, NY, USA

${ }^{3}$ Service of Interventional Neuroradiology, Departments of Neurosurgery, Neurology and Radiology, Weill Cornell Medical College of New York-Presbyterian Hospital, New York, NY, USA

${ }^{4}$ Department of Ophthalmology, Weill Cornell Medical College of New York-Presbyterian Hospital, New York, NY, USA

${ }^{5}$ Department of Ophthalmology, Mount Sinai School of Medicine, New York, NY, USA

\begin{abstract}
There is growing interest in intravitreal injections of chemotherapy for retinoblastoma. However, concerns for potential tumor seeding through the needle track has prompted the use of risk-reducing precautionary methods. Presented here is a novel technique, which can be easily replicated, requires minimal sophisticated equipment and with laboratory data supporting its concept. Sterile distilled water submersion for 3 minutes renders retinoblastoma cells nonviable and can be employed as a precautionary method following intravitreal injection in the technique described here.
\end{abstract}

Keywords: Cancer, chemotherapy, distilled water, fine needle aspiration, intravitreal injection, melphalan, retinoblastoma, water.

\section{INTRODUCTION}

Despite historical trepidation, there is growing interest in the use of intravitreal injections of chemotherapy for the treatment of retinoblastoma. This has mostly been explored for eyes with vitreous seeding [1-8], which have notoriously poor rates of globe preservation. While ophthalmic artery chemosurgery has proven to be effective for these eyes (with an ocular survival of $64 \%$ in naïve eyes with vitreous seeding only) [9], the use of intravitreal melphalan has a reported initial ocular salvage rate as high as $83 \%$, surpassing all other treatment modalities for eyes that recur or persist despite current treatment modalities $[1,2]$.

However, intravitreal injections disrupt the natural barrier of the eye and there is concern for potential tumor seeding through the needle track. For example, retinoblastoma cells have been detected in the needle track of ex vivo postenucleation specimens $[10,11]$. Even though the viability of in vivo escaped cells is unknown, there are cases of extraocular retinoblastoma disease following both diagnostic and therapeutic intravitreal procedures $[1,2,12,13]$.

Various techniques have been developed to limit the risk of extraocular dissemination when intravitreal injections are given $[1-3,7,14,15]$. These methods are intended to prophylactically lower the risk of tumor cell escape, and/or,

*Address correspondence to this author at the Ophthalmic Oncology Service, Memorial Sloan-Kettering Cancer Center, 70 East 66th Street, New York, NY 10065, USA; Tel: (212) 744 1700; Fax: (212) 734 2553;

E-mail: francij1@mskcc.org to target the destruction of leaked cells. The effectiveness of these techniques is unclear and many are not without local repercussions for the eye. We have developed a novel alternative technique, requiring limited sophisticated resources. It consists of submerging the eye in an irrigating reservoir of sterile distilled water in which retinoblastoma cells die. Here we describe this method and offer data that supports its efficacy.

\section{METHODS}

Six eyes ( 1 eye Reese-Ellsworth (RE) Group VA and 5 eyes RE Group VB; 3 eyes International Classification (IC) $\mathrm{D}$ and 3 eyes IC E) of six patients ( 3 male and 3 female, mean age 79 mos (range 17-213 mos)) underwent 20 weekly intravitreal melphalan injections. All patients had bilateral retinoblastoma and 4 were monocular. All eyes had received ophthalmic artery chemosurgery (OAC) and had vitreous seeds refractory to treatment. At the time of injection the patient was positioned supine and digital massage performed to bring the intraocular pressure to less than $10 \mathrm{mmHg}$ confirmed by Tonopen. The eye was then prepped in a sterile fashion, the lashes draped and the lid speculum placed. The injection location in the superior meridian was selected in an area that was free of tumor by ophthalmoscopy and by UBM. At $3.5 \mathrm{~mm}$ posterior to the limbus, melphalan $30 \mathrm{mcg} / 0.7 \mathrm{cc}$ was injected with a 33 -gauge needle. Single freeze-thaw cryotherapy was applied to the ocular surface to seal and sterilize the injection site with an encompassing ice ring, as the needle was withdrawn. 


\section{Technique}

The necessary equipment is depicted in Fig. (1). With the lid speculum in place following injection, sterile distilled water drawn into a $60 \mathrm{cc}$ syringe was lightly irrigated over the eye to fully submerge it in liquid (Fig. 2). Irrigation with submersion was continued for at least 3 minutes. The effluent was carefully collected into a kidney basin and sent for cytopathological evaluation. Care was taken to place no undue pressure on the eye to prevent efflux of intraocular contents.

\section{In Vitro Validation of Principle}

Retinoblastoma cell line Y79 was cultured in RB culture medium consisting of IMDM with 10\% FBS (Sigma, St. Louis MO), 1\% Penicillin/streptomycin, $2 \mathrm{mM}$ glutamine, $55 \mu \mathrm{M}$ beta-mercaptoethanol (Invitrogen), as described [16], at $37^{\circ} \mathrm{C}$ in a humidified incubator with $5 \% \mathrm{CO}_{2}$. Mixture of $300 \mathrm{nM}$ 4',6-diamidino-2-phenylindole (DAPI) and $1 \mathrm{mg} / \mathrm{ml}$ Propidium Iodide (PI) were prepared in phosphate buffered saline (PBS) or sterile distilled water $\left(\mathrm{dH}_{2} \mathrm{O}\right)$. Y79 cells were collected in $1.5 \mathrm{ml}$ Eppendorf tubes with $10^{6}$ cells per tube. Cells were spun down and medium was removed. $0.5 \mathrm{ml}$ $\mathrm{ddiH}_{2} \mathrm{O}$ or PBS with DAPI/PI was added to $\mathrm{Y} 79$ in
Eppendorf tube, mixed, and immediately transferred to a hemacytometer. Photographs of DAPI and PI fluorescent staining were taken every half-minute with a fluorescent microscope (Zeiss Imager. Z2). A similar procedure was also carried out for uveal melanoma lines OCM1 and C918.

\section{RESULTS}

Cytopathological results revealed no malignant cells in all 20 specimens. There were squamous cells in 3 specimens, red blood cells (RBCs) in 1 specimen and inflammatory cells in 2 specimens. During submersion, all eyes developed clinically apparent cornea edema with stromal haze that resolved approximately one hour later. One injection was accompanied with a subconjunctival hemorrhage, corresponding to the effluent specimen containing RBCs. At a median of 14.8 mos, no tumor growth was observed in the subconjunctival space nor at the needle site.

Results of in vitro Y79 cells in sterile distilled deionized water are shown in Fig. (3), demonstrating more than $99 \%$ of cells were nonviable by 3 minutes. The control group involving Y79 cells in PBS is depicted in Fig. (4) and shows more than $80 \%$ of cells were still viable by 3 minutes. Both uveal melanoma cells OCM1 and C918 remained viable after

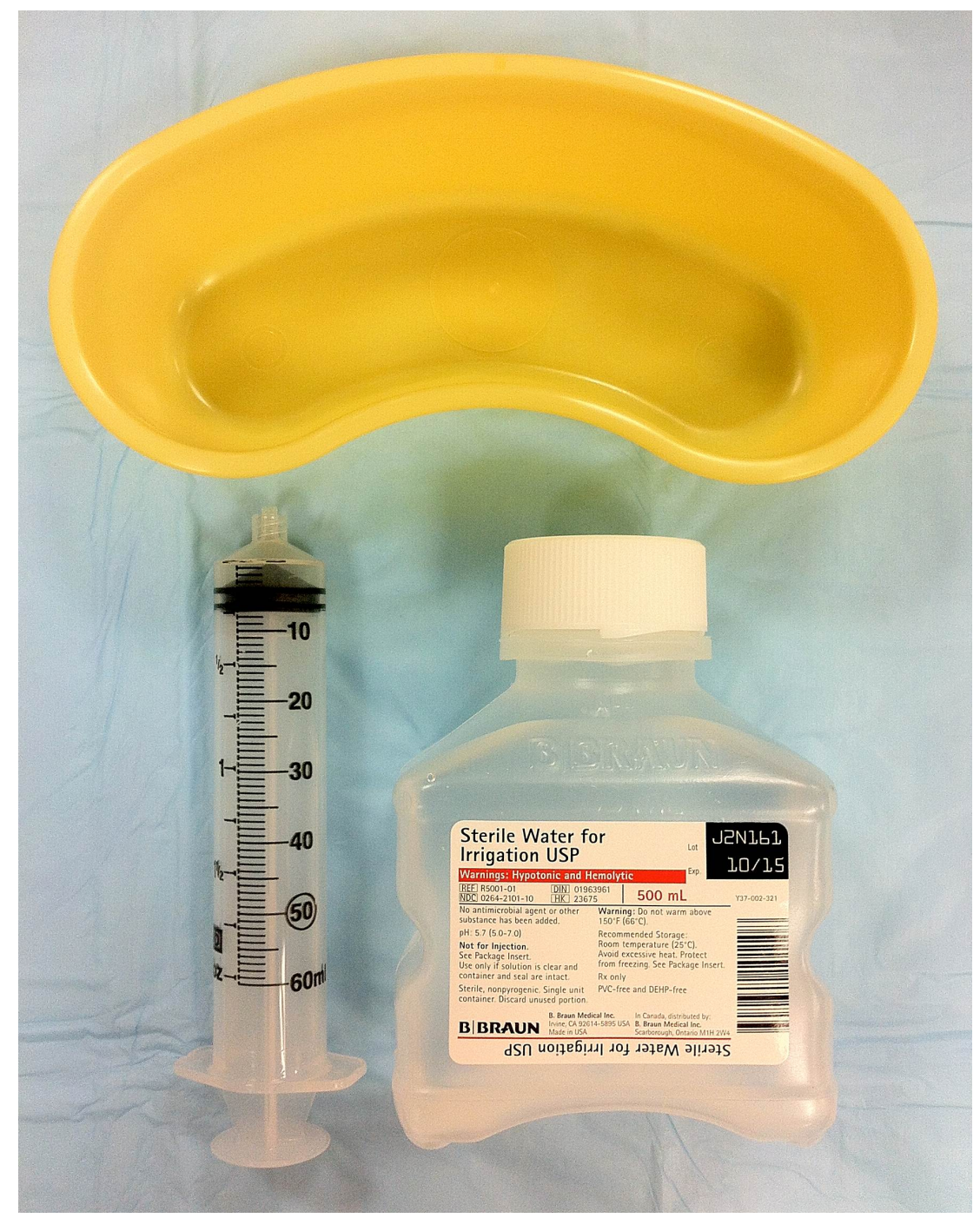

Fig. (1). Equipment for the water submersion technique includes a $60 \mathrm{cc}$ syringe, sterile distilled water and a kidney basin. 


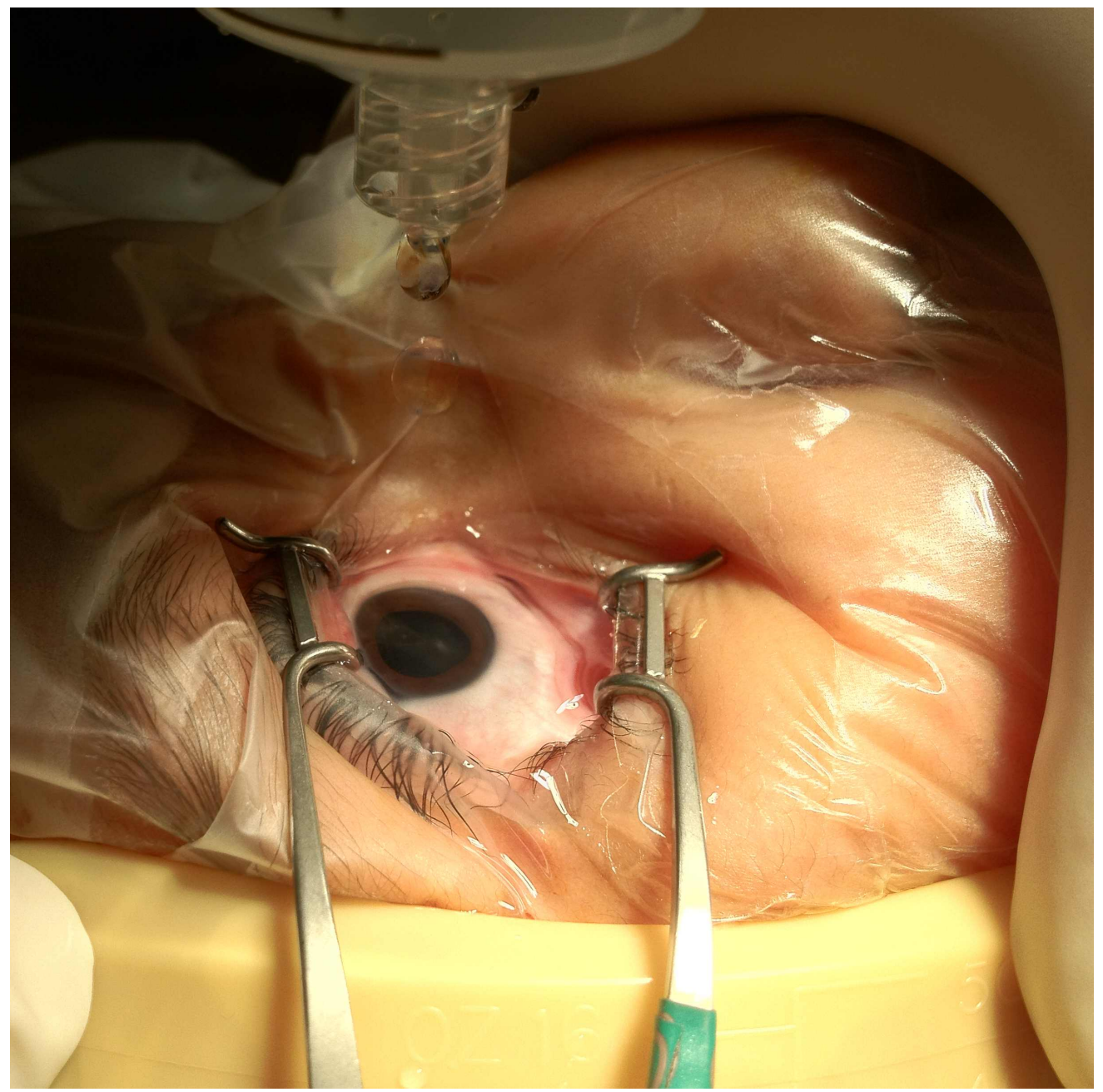

Fig. (2). Water submersion technique: sterile distilled water is irrigated from 60 cc syringe onto a submerged eye with effluent collecting in kidney basin.

immersion in PBS for 20 minutes; and both were approximately $90 \%$ nonviable by 10 minutes of immersion in $\mathrm{ddiH}_{2} \mathrm{O}$.

\section{Comment}

The introduction of a needle into a retinoblastoma eye for diagnostic or therapeutic purposes may employ needles of differing sizes (25-27 gauge for fine needle aspiration biopsy (FNAB) [11], and 30-33 gauge for delivery of medication [17]). There is a fear that tumors cells may seed the needle track and disseminate to cause extraocular disease. Reassuringly, we did not discover any malignant cells in our samples of effluent. However, this ominous complication has been reported in scattered cases of reitnoblastoma: Henkes describes a case of extraocular retinoblastoma following FNAB [13], Eide reports on "extraocular drippings" of retinoblastoma with FNAB [12], Makley writes of disease extension through a scleral incision [18] and Kaneko and Susuki have one patient of 237 injected eyes with subconjunctival spread following a therapeutic injection $[2,19]$.

There are techniques to reduce the risk of tumor escape; however, some may have inherent adverse consequences for the eye. For instance, besides scarring, cryotherapy to the injection site (typically at the pars plana) may subject the ciliary body to repetitive, weekly freezing and possibly place the eye at risk for hypotony; an anterior chamber paracentesis may create a transient hypotony but introduces yet another needle in to the eye; and injecting a subtenon deposit of chemotherapy may have similar repercussions to periocular chemotherapy which include transient periorbital edema, pseudocellulitis, fat necrosis, fibrosis, mechanical restriction and optic atrophy [20-23].

We report on a simple principle validated in vitro and translated into a novel precautionary technique for intravitreal injection of retinoblastoma eyes. We show that more than $99 \%$ of retinoblastoma Y79 cells become nonviable after 3 minutes in sterile distilled water - in contrast to $80 \%$ viability at 3 minutes of PBS instillation. The likely explanation is retinoblastoma cell lysis in the hypotonic environment of water, and cell membrane distortion in the presence of a high dielectric constant from $\mathrm{dH} 20$. This principle has demonstrated utility in the cell lysis of other tumors [24]. Submerging the eye in sterile distilled water for 3 minutes following intraocular injection, as outlined in this report, should theoretically kill any retinoblastoma cells that may have emerged. Hypothetically, this technique may also be utilized during ophthalmic surgery if an inadvertent 


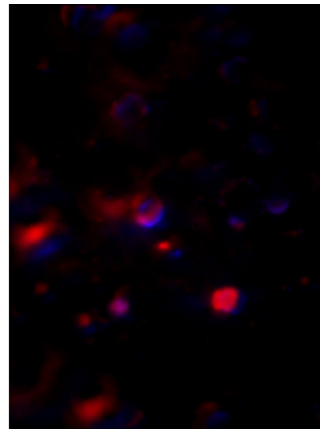

$0.5 \mathrm{~min}$

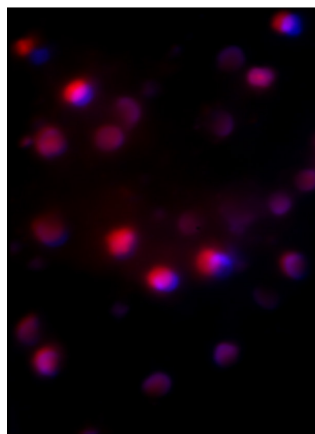

$2.5 \mathrm{~min}$

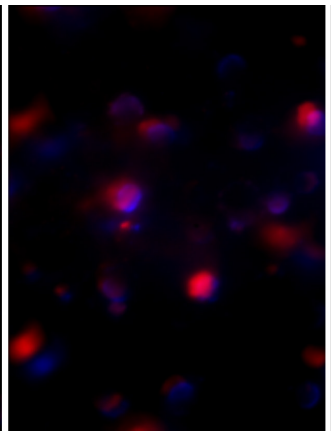

$0.75 \mathrm{~min}$

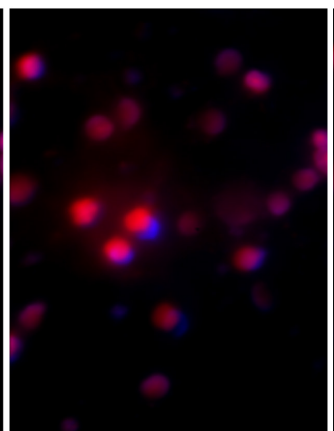

$3.0 \mathrm{~min}$

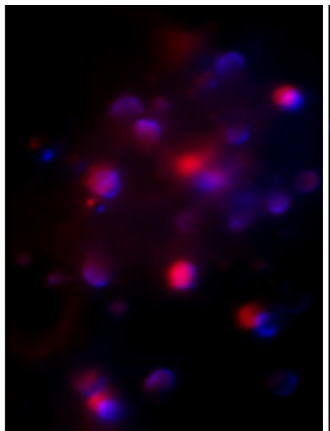

$1.0 \mathrm{~min}$

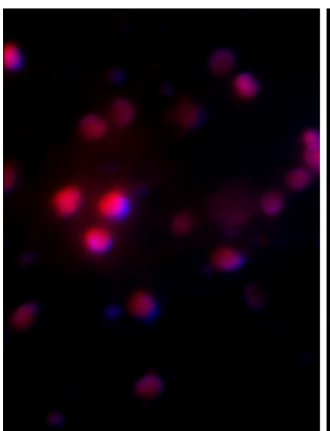

$3.5 \mathrm{~min}$

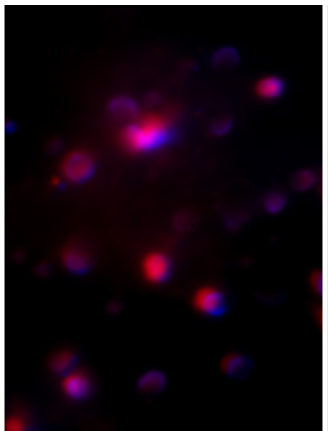

1.5 mins

2.0 mins

Fig. (3). DAPI (blue) and PI (red) staining of Y79 retinoblastoma cells in sterile distilled deionized water at various time points, demonstrating more than $99 \%$ of cells are nonviable by 3 minutes.

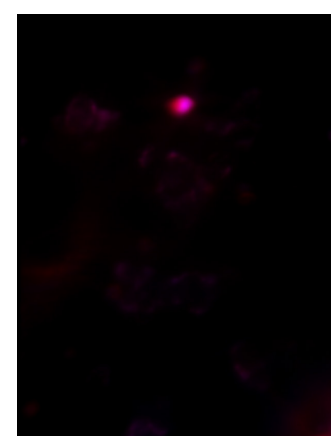

$0.5 \mathrm{~min}$

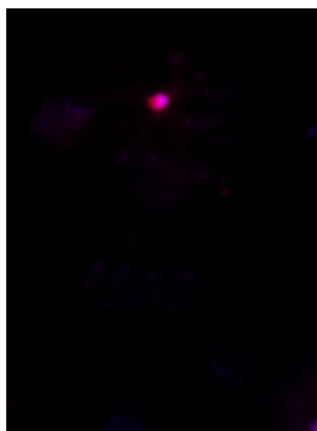

3.0 mins

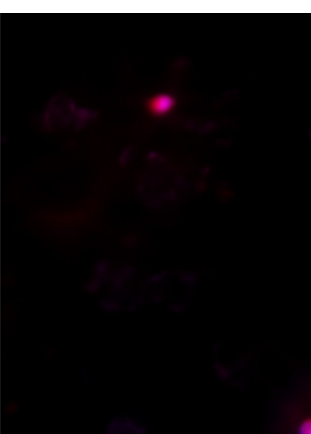

$1.0 \mathrm{~min}$

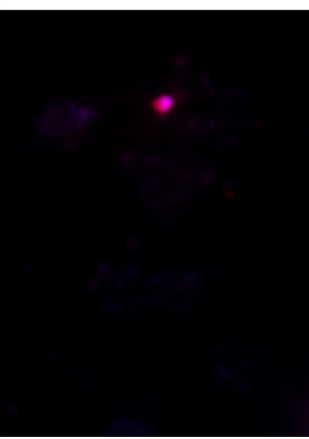

3.5 mins

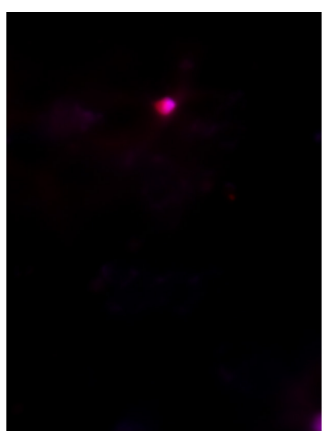

1.5 mins

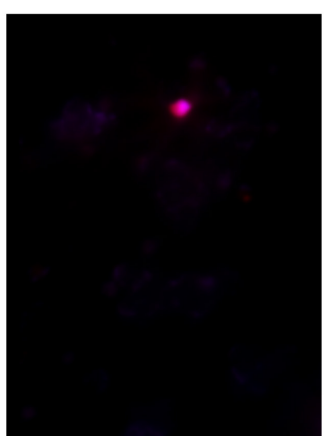

4.0 mins

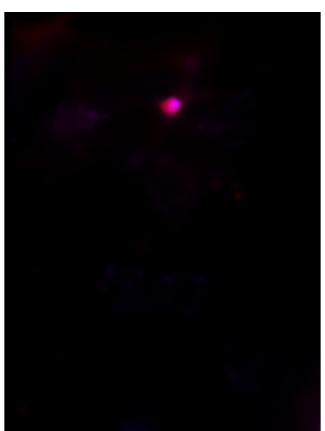

\section{0 mins}

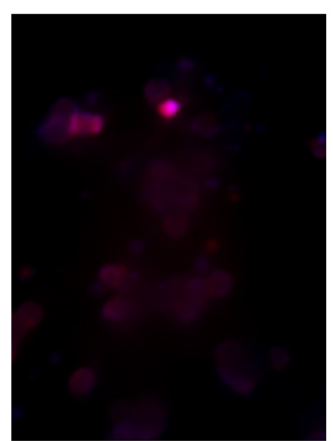

5.0 mins

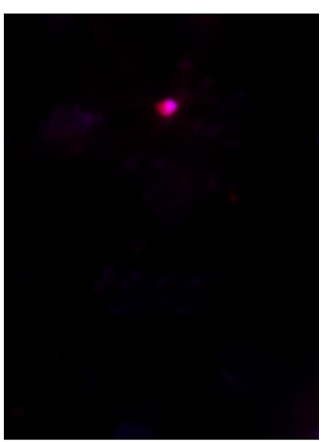

2.5 mins

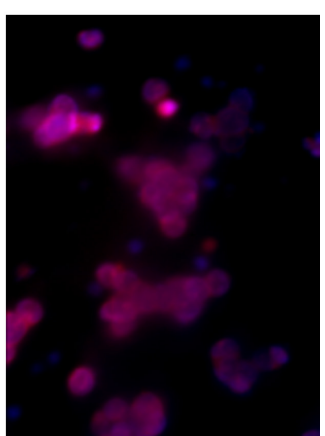

10.0 mins

Fig. (4). DAPI (blue) and PI (red) staining of Y79 retinoblastoma cells in PBS at various time points, showing more than $80 \%$ of cells are still viable by 3 minutes.

penetrating puncture is created. The observed adverse effect was temporary, consisting of transient corneal edema that resolved with time.
Sterile distilled water submersion provides an effective way to kill retinoblastoma cells on the surface of the eye, may be of use during penetrating procedures on affected eyes, requires minimal resources and is easy to replicate. 


\section{CONFLICT OF INTEREST}

The authors confirm that they do not have any conflict of interest.

\section{ACKNOWLEDGEMENTS}

This work was supported by The Fund for Ophthalmic Knowledge and the New York Community Trust. We would like to thank Rosa Chu for her assistance on this project. Dr. Jasmine Francis had full access to all the data in the study and takes responsibility for the integrity of the data and the accuracy of the data analysis.

\section{REFERENCES}

[1] Munier FL, Gaillard MC, Balmer A, et al. Intravitreal chemotherapy for vitreous disease in retinoblastoma revisited: from prohibition to conditional indications. $\mathrm{Br} \mathrm{J}$ Ophthalmol 2012; 96(8): 1078-83.

[2] Munier FL, Soliman S, Moulin AP, Gaillard MC, Balmer A, BeckPopovic M. Profiling safety of intravitreal injections for retinoblastoma using an anti-reflux procedure and sterilisation of the needle track. Br J Ophthalmol 2012; 96 (8): 1084-7.

[3] Ghassemi F, Shields CL. Intravitreal melphalan for refractory or recurrent vitreous seeding from retinoblastoma. Arch Ophthalmol 2012; 130(10): 1268-71.

[4] Suzuki S, Kaneko A. Management of intraocular retinoblastoma and ocular prognosis. Int J Clin Oncol 2004; 9(1): 1-6.

[5] Kaneko A, Suzuki S. Eye-preservation treatment of retinoblastoma with vitreous seeding. Jpn J Clin Oncol 2003; 33(12): 601-7.

[6] Seregard S, Kock E, af Trampe E. Intravitreal chemotherapy for recurrent retinoblastoma in an only eye. Br J Ophthalmol 1995; 79(2): 194-5.

[7] Kivelä T, Eskelin S, Paloheimo M. Intravitreal methotrexate for retinoblastoma. Ophthalmology 2011; 118(8): 1689.e1-6.

[8] Brodie SE, Munier FL, Francis JH, Marr B, Gobin YP, Abramson $\mathrm{DH}$. Persistence of retinal function after intravitreal melphalan injection for retinoblastoma. Doc Ophthalmol 2013; 126(1): 79-84.

[9] Abramson DH, Marr BP, Dunkel IJ, et al. Intra-arterial chemotherapy for retinoblastoma in eyes with vitreous and/or subretinal seeding: 2-year results. Br J Ophthalmol 2012; 96(4): 499-502.
[10] Karcioglu ZA, Gordon RA, Karcioglu GL. Tumor seeding in ocular fine needle aspiration biopsy. Ophthalmology 1985; 92(12): 17637.

[11] Karcioglu ZA. Fine needle aspiration biopsy (FNAB) for retinoblastoma. Retina (Philadelphia, Pa.) 2002; 22(6): 707-10.

[12] Eide N, Syrdalen P, Walaas L, Hagmar B. Fine needle aspiration biopsy in selecting treatment for inconclusive intraocular disease. Acta Ophthalmol Scand 1999; 77 (4): 448-52.

[13] Henkes HE, Manschot WA. The danger of diagnostic biopsy in eyes suspected of an intraocular tumour. Ophthalmologica 1963; 145: 467-9.

[14] Char DH, Miller TR. Fine needle biopsy in retinoblastoma. Am J Ophthalmol 1984; 97 (6): 686-90.

[15] Smith SJ, Pulido JS, Salomão DR, Smith BD, Mohney B. Combined intravitreal and subconjunctival carboplatin for retinoblastoma with vitreous seeds. Br J Ophthalmol 2012; 96(8): 1073-7.

[16] DiCiommo DP, Duckett A, Burcescu I, Bremner R, Gallie BL. Retinoblastoma protein purification and transduction of retina and retinoblastoma cells using improved alphavirus vectors. Invest Ophthalmol Vis Sci 2004; 45(9): 3320-9.

[17] Smith SJ, Smith BD. Evaluating the risk of extraocular tumour spread following intravitreal injection therapy for retinoblastoma: a systematic review. Br J Ophthalmol 2013; 97(10):1231-6.

[18] Makley TA. Biopsy of intraocular lesions. Am J Ophthalmol 1967; 64(3): 591-9.

[19] Seregard S, Singh AD. Retinoblastoma: direct chemotherapeutic drug delivery into the vitreous cavity. Br J Ophthalmol 2012; 96 (4): 473-4.

[20] Leng T, Cebulla CM, Schefler AC, Murray TG. Focal periocular carboplatin chemotherapy avoids systemic chemotherapy for unilateral, progressive retinoblastoma. Retina (Philadelphia, $\mathrm{Pa}$.) 2010; 30 (Suppl 4): S66-8

[21] Schmack I, Hubbard GB, Kang SJ, Aaberg TM, Grossniklaus HE. Ischemic necrosis and atrophy of the optic nerve after periocular carboplatin injection for intraocular retinoblastoma. Am J Ophthalmol 2006; 142(2): 310-5.

[22] Mulvihill A, Budning A, Jay V, et al. Ocular motility changes after subtenon carboplatin chemotherapy for retinoblastoma. Arch Ophthalmol 2003; 121(8): 1120-4

[23] Abramson DH, Frank CM, Dunkel IJ. A phase I/II study of subconjunctival carboplatin for intraocular retinoblastoma. Ophthalmology 1999; 106(10): 1947-50.

[24] Ito F, Camoriano M, Seshadri M, Evans SS, Kane JM, Skitzki JJ. Water: a simple solution for tumor spillage. Ann Surg Oncol 2011; 18(8): 2357-63. 